\title{
Isolierung löslicher Antigene durch spezifische Immunabsorption
}

\author{
Von K. Schumacher und W. Schneider. \\ Aus der Medizinischen Universitätsklinile Köln (Direktor: Prof. Dr. R. Gross)
}

(Eingegangen am 11. Dezember 1968)

Es wird über eine Methode zur Isolierung von Antigenen oder Antikörpern aus Proteingemischen oder Anti-Seren berichtet. Merkmale der Methode sind die Immunabsorption, die Hydrolyse des Antigen-Antikörper-Komplexes im sauren Milieu und die präparative Trennung durch Molekularsiebung. Die Methode wurde zur Isolierung organspezifischer Antigene aus der löslichen Zytoplasmafraktion von Human-Leber verwendet. Voraussetzung zur Gewinnung reiner Antigene sind dabei monospezifische Antikötpcr, die durch Absorption von Anti-Seren mit zahlreichen Organ-Antigenen gewonnen wurden.

\section{The isolation of soluble antigens by specific immunoabsorption}

A method for the isolation of antigens or antibodies from protein mixtures or antisera is described. The main features of the method are immunabsorption, acid hydrolysis and gel-filtration. With the aid of this method an organ-specific- antigen from the soluble cytoplasma of human liver was isolated. To obtain pure antigens, monospecific antibodies were prepared by absorption of the antisera with multiple antigens from other organs.

Während für den Nachweis von Antikörpern (1-9) und die Isolierung antikörperhaltiger Immunglobulinfraktionen zahlreiche Methoden zur Verfügung stehèn (11-13), bereitet die Isolierung reiner Antigene, insbesondere aus Geweben, große experimentelle Schwierigkeiten. Es soll deshalb über eine Methode zur Isolierung löslicher Antigene aus Human-Leber berichtet werden, bei der wir Immunabsorption und Molekularsiebung im sauren Milieu kombinierten.

\section{Methodik}

\section{Herstcllung des Antiserums}

$2,5 \mathrm{~kg}$ schwere Kaninchen wurden mit löslichem Zytoplasma aus Human-Leber (14) unter Zusatz gleichen Volumens einer 2proz. Alumininiumhydroxydlösung immunisiert. Die Tiere erhielten $2 \mathrm{mal} 10 \mathrm{mg}$ Antigenprotein sụbcutan $2 \mathrm{mal}$ wöchentlich. Blutentnahmen aus der Unterschenkelvene der Hinterbeine wurden am 20. und 40. Tag nach Beginn der Immunisierung durchgeführt.

Nach Prüfung der Antiseren auf ihrẹe Antikörperaktivität durch Ansatz in Verdünnungsstufen mit Hilfe der Doppeldiffusion (8) gegen lösliches Zytoplasma aus Human-Leber, -Niere, -Herzmuskel, -Skelettmuskel, -glatte Muskulatur, -Schilddrüse sowie gegen Kerne, Mitochondrien und Mikrosomen aus HumanLeber wurden die Antiseren entsprechend ihren Titern gegen die verschiedenen Antigene mit diesen Antigenen stufenweise bis zur Erschöpfung absorbiert durch Zugabe von lyophilisierten Antigenen.

Immunabsorption und Fraktionierung von Antigen-Antikörper-Komplexen durch Hydrolyse im sauren Milieu

Absorbierte Antiseren und Antigenlösung, eingestellt aưf gleichen Proteingehalt $(40 \mathrm{mg} / \mathrm{ml})$ wurden im Verbältnis $5: 1$ vereinigt, gut gemischt und 2 Tage bei $4^{\circ}$ inkubiert. Das danach entstandene Präzipitat wurde abzentrifugiert ( $30 \mathrm{Min}$. bei $10000 \mathrm{~g}$ ) und $3 \mathrm{mal}$ mit eiskalter 0,9proz. $\mathrm{NaCl}$-Lösung gewaschen. Anschließend wurde das Präzipitat in Glycinpuffer $\mathrm{pH} 3,2(0,1 \mathrm{M}$ Glykokoll + $0,1 \mathrm{M} \mathrm{NaCl}$, mit $0,1 \mathrm{~N} \mathrm{HCl}$ auf $\mathrm{pH} 3,2$ eingestellt) gelöst.

\section{Gelfiltration}

Die Fraktionierung der hydrolysierten Antigen-AntikörperKomplexe wurde durch Molekularsiebung an Sephadex G-200 (Pharmacia, Uppsala) durchgeführt (15). Säule $1000 \times 30 \mathrm{~mm}$ Puffer: $0,1 \mathrm{M}$ Glykokoll, $0,1 \mathrm{M} \mathrm{NaCl} \mathrm{pH} \mathrm{3,2.} \mathrm{Elution} \mathrm{mit} 8 \mathrm{~m} /$ Stunde, Kühlung $4^{\circ}$. Photometrie der Fraktionen bei $280 \mathrm{~nm}$. Zur annähernden Bestimmung des Molekulargewichtes wurde dic Gelpackung mit Substanzen bekannten Molekulargewichtes geeicht. An Hand der Eichkurve ergab sich aus den Elutionsvolumina das Maß für das Molekulargewicht (16).

\section{Immunelektrophoresen}

Die elektrophoretische Analyse wurde mit Hilfe der ObjektträgerMethode nach ScherdegGer (17) durchgeführt. Agar 1,5proz. (Reinagar Behring-Werke, Marburg) in $0,01 \mathrm{M}$ Na-BarbituratPuffer, pH 8,6+Cialit 1:10000. Elektrodenpuffer: 0,1 $\mathrm{M} \mathrm{Na}$ Barbiturat-Puffer $\mathrm{pH} 8,6$. Die Elektrophorese erfolgte in $60 \mathrm{Min}$. bei $12 \mathrm{~mA} /$ Plattenrahmen (LKB-Producter, Stockholm) und etwa 250 Volt. Nach Einfüllen von $80 \mu$ l Antiserum erfolgte die Diffusion bei $4^{\circ}$ in der Feuchtkammer für $48 \mathrm{Stdn}$. Die Dokumentation der Präzipitationsbanden wurde durch Photographie der ungefärbten Plättchen im schräg einfallenden Durchlicht vorgenommen.

Proteinbestimmungen wurden nach Lowry (18) durchgeführt.

\section{Ergebnisse}

Nach Mischen des absorbierten Antiserums mit löslichem Zytoplasma aus Human-Leber kam es innerhalb 48 Stunden $\mathrm{zu}$ einem feinflockigen Niederschlag, der sich nach Abzentrifugieren in Glycin-Puffer $\mathrm{pH} 3,2$ quantitativ lösen ließ. Der jeweils in einem möglichst kleinen Volumen gelöste Komplex wurde auf die Gelpackung aufgetragen und im sauren Milieu fraktioniert (Abb. 1). Das Elutions-Diagramm zeigte 2 gut voneinander getrennte Fraktionen. Die immunelektrophoretische Analyse dieser Fraktionen ergab, daß Fraktion I weder mit Anti-Human-Serum, noch mit nicht-absorbiertem Anti-Human-Leber-Zytoplasma-Serum reagierte. $\mathrm{Da}$ ein Antiserum gegen Kaninchen $\gamma$-Globulin nicht zur Verfügung stand, konnte diese Fraktion immunologisch nicht identifiziert werden. Das Elutionsvolumen dieser Fraktion entsprach einem Molekulargewicht von etwa 150000 (Abb. 2).

Die II. Fraktion nach Gel-Filtration ergab in der Immunelektrophorese mit Anti-Human-Serum ebenfalls keine Reaktion. Mit Anti-Leber-Zytoplasma-Serum fand sich jedoch eine Präzipitationsbande unter dem Startloch. Die glëiche Bande entstand auch, nachdem das Antiserum mit Human-Serum, -Niere, -glatter Muskulatur, -Herz und Skelettmuskel absorbiert worden war (Abb. 3). 


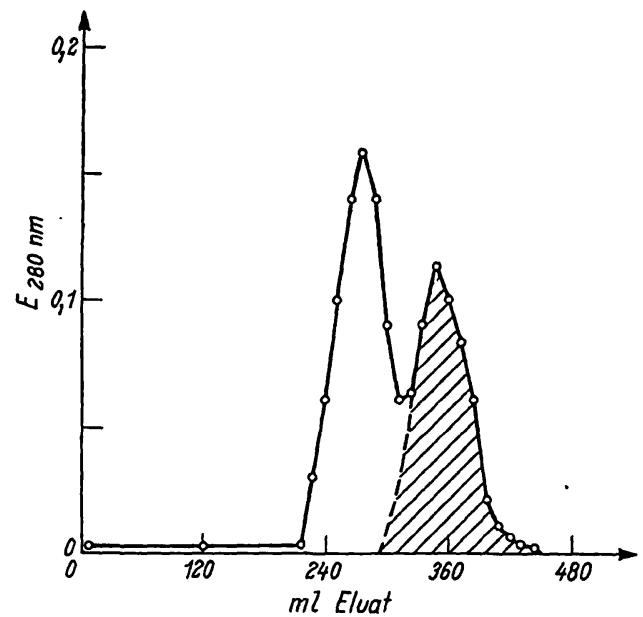

Abb. 1

Fraktionierung eines Antigen-Antikörper-Komplexes durch MoluFursiebung im sauren Milieu. Fraktion I durfte den Antikörper aus Kaninchen-Serum enthalten. Fraktion II (schwarz markiert) enthält ein organspezifisches Antigen aus Human-Leber-Zytoplasma

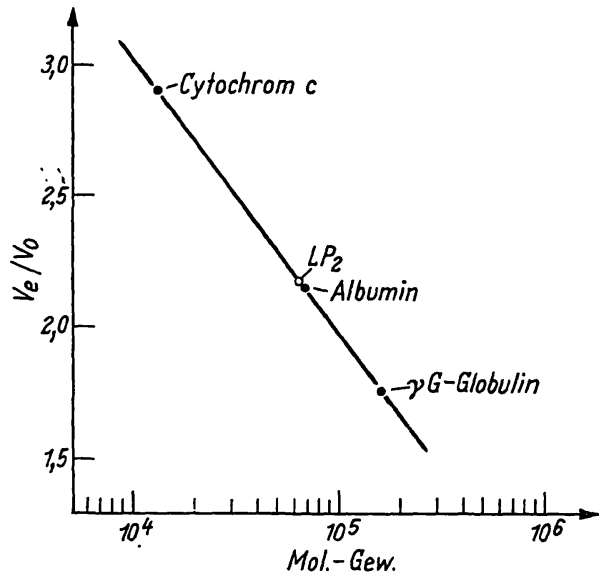

Abb. 2

Molekulargewichts-Bestimmung des isolierten Antigens aus HumanLeber an einer geeichten Gelsäule

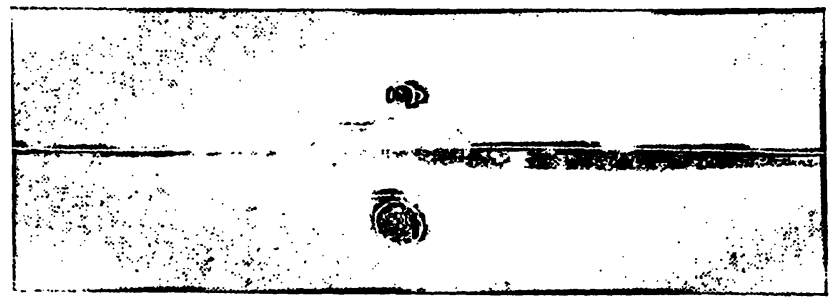

Abb. 3

Immunelektrophoretische Analyse der Fraktion II nach Molekularsiebung, oben: Human-Leber-Zytoplasma, unten: Isoliertes Leber mit Human-Serum, Human-Niere, Herz- und Skelettmuskel
Allerdings fielen die Präzipitationsbanden relativ schwach aus.

Nach dem Elutionsvolumen an der geeichten Gelsäule dürfte das Molekulargewicht der in der II. Fraktion eluierten Substanz, einer Größenordnung von etwa 70000 entsprechen.

\section{Diskussion}

Die Isolierung reiner Antigene durch Immunabsorption setzt monospezifische Antiseren voraus. Durch $\mathrm{Ab}$ sorption unserer Antiseren gelang es, eine Antiserum herzustellen, das nur noch mit einem Antigen aus der löslichen Zytoplasma-Fraktion reagierte. Der mit dem monospezifischen Antiserum gebildete Antigen-Antikörper-Komplex enthielt ein Antigen, das nach Hydrolyse des Komplexes als elektrophoretisch, immunelektrophoretisch und nach Molekularsiebung einheitliches Protein angesehen werden muß. Mit Hilfe dieser Methode ist also, unter Verwendung monospezifischer Antiseren, eine Antigen-Isolierung aus Proteingemischen möglich. Gleicherweise müßte es möglich sein, unter Verwendung reiner Antigene auch die entsprechenden spezifischen Antikörper aus einem Antiserum $\mathrm{zu}$ isolieren.

Sowohl Antikörper als auch Antigene bleiben während des ganzen Isolierungsverfahrens, mit Ausnahme während der Phase der Komplexbildung, wasserlöslich. Eine Änderung der immunologischen Spezifität durch das Trennverfahren wurde nicht beobachtet.

$\mathrm{Ob}$ Unterschiede dieser Methode gegenüber anderen Verfahren, die mit wasserunlöslichen Reaktanden arbeiten (19) bezüglich der Ausbeute bestehen, wird vergleichend geprüft.

Das aus der löslichen Zytoplasmafraktion von HumanLeber isolierte Antigen ist nach seiner immunologischen Spezifität als organspezifisch anzusehen. Es unterscheidet sich in der elektrophoretischen Wanderungsgeschwindigkeit etwas von einem durch chromatographische Verfahren isolierten Leberprotein (14); in ihrer Molekülgröße unterscheiden sich die beiden LeberAntigene dagegen nur wenig. Untersuchungen über weitere chemische Eigenschaften dieser Antigene stehen noch aụs.

Wir danken der Deutschen Forschungsgemeinschaft für die Unterstützung dieser Arbeit.

\section{Literatur}

1. Kolmer, J. A., Amer. J. Publ. Health 26, 126 (1936). - 2. WAALER, E., Acta med. scand. 17, 172 (1940). - 3. Rose, H. M., Ch. Ragan, E. Pearce und M. O. Lipman, Proc. Soc. exp. Biol. Med. (N. Y.) 68, 1 (1948). - 4. BoYden, S. U., J. Exper. Med. 93, 107 (1951). - 5. SCheifFARTH, F. und F. LEGLER, Ärztl. Wschr. 6, 660 (1951). - 6. Miescher, P. und M. FAUCONNET, Experientia (Basel) 10, 252 (1954). - 7. SINGER, J. M. und Ch. M. Plotz, Arthr. Rheumat. (N. Y.) 1, 142 (1958). 8. Ouchterlony, O., Diffusion in gel methods for immunological analysis. In: P. Kallos: Progress in Allergy, S. Karger, Basel, New York (1958). - 9. StefFEN, C., Klin. Wschr. 40, 613 (1962). 10. Sober, H. A. und E. A. Peterson, Federation Proc. 17, 1116
(1958). - 11. Herde, K. und H. HAUpT, Behring-Werke Mitteil. 43, 161 (1964). - 12. Schumacher, K., diese Z. 4, 196 (1966). 13. Schumacher, K., Klin. Wschr. 45, 1045 (1967). - 14. SchuMACHER, K. und W. SchNeIDER, Klin. Wschr. 1969 (im Druck). 15. Flodin, P. und J. Kirlander, Biochim. biophysica Acta, Amsterdam 63, 403 (1962). - 16. Iwatsubo, M. und A. CuRdel, C. R. Acad. Sci. (Paris) 256, 5224 (1963). - 17. ScherdegGer, J. J., Int. Arch. Allergy (Basel) 7, 103 (1955). - 18. Lowry, O. H., M. J. Rosebrough, A. L. Faber und R. J. Randall, J. biol. Chemistry 193, 265 (1951). - 19. Avrameas, S. und T. Ternynk, J. biol. Chemistry 242, 1651 (1967).

Priv. Doz. Dr. K. Schumacher $5000 \mathrm{Köln}$-Lindenthal Josef-Stelzmann-Str. 9 